\title{
Cloning and expression of a new recombinant thrombolytic and anthithrombotic agent - a staphylokinase variant
}

\author{
Michał Kowalski ${ }^{1}$, George Brown ${ }^{1}$, Magdalena Bieniasz ${ }^{1}$, Katarzyna Oszajca ${ }^{1}$, \\ Ewa Chabielska², Tadeusz Pietras ${ }^{2}$, Zofia Szemraj ${ }^{3}$, Eusebio Makandjou-Ola1, \\ Jacek Bartkowiak ${ }^{1}$ and Janusz Szemraj ${ }^{1 凶}$ \\ ${ }^{1}$ Department of Medical Biochemistry, and ${ }^{3}$ Department of Pneumology and Allergy, Medical University of \\ Lodz, Łódź, Poland; ${ }^{2}$ Department of Biopharmacy Medical University of Bialystok, Białystok, Poland
}

Received: 24 April, 2008; revised: 09 September, 2008; accepted: 18 September, 2008 available on-line: 19 November, 2008

\begin{abstract}
To develop a more potent antithrombin agent with thrombolytic and antiplatelet properties, a new staphylokinase (SAK) variant was constructed. The kringle 2 domain (K2) of tissue typeplasminogen activator (t-PA) containing a fibrin-specific binding site (i), the RGD sequence (ArgGly-Asp) for the prevention of platelet aggregation (ii) and the antithrombotic agent - hirulog (iii) was assembled to the C-terminal part of recombinant staphylokinase (r-SAK). cDNA for the hybrid protein SAK-RGD-K2-Hirul was cloned into Pichia pastoris pPIC9K yeast expression vector. The introduction of $\mathrm{K} 2 \mathrm{t}-\mathrm{PA}$, the RGD sequence and hirulog into the C-terminus of r-SAK did not alter the staphylokinase activity. We observed a higher clot lysis potency of SAK-RGDK2-Hirul as evidenced by a faster and more profound lysis of ${ }^{125} \mathrm{I}$-labeled human fibrin clots. The potency of thrombin inhibition by the hirulog C-terminal part of the recombinant fusion protein was almost identical to that of r-Hir alone. These results suggest that the SAK-RGD-K2-Hirul construct can be a more potent and faster-acting thrombolytic agent with better antithrombin and antiplatelet properties compared to r-SAK and SAK-RGD-K2-Hir.
\end{abstract}

Keywords: recombinant protein, thrombolysis, thrombolytic and antithrombotic agents, antiplatelet activity, staphylokinase, hirulog, K2 domain of t-PA

\section{INTRODUCTION}

Thromboembolism is a major disease in developed countries, such as Western European countries and the USA, and is generally treated by means of thrombolytic therapy, which made application of the body's intrinsic fibrinolytic system. The incidence of coronary heart disease has been constantly increasing recently, becoming the major disease that imperils human life. As a life-threatening occurrence it often requires aggressive pharmacological treatment, thrombolytic therapy being the obvious rationale. The most common strategy of thrombolytic therapy involves activation of the fibrinolytic system by in- fusing plasminogen activators (Collen et al., 2000; Veshina et al., 2006) that convert plasminogen to the proteolytic enzyme plasmin and initiate clot lysis. The large scale application of molecular biology techniques in the 1980s initiated a dynamic development of research aiming at 'improving' the properties of natural proteins, as well as engineering new proteins to be applied as thrombolytic agents. A frequent problem in thrombolytic therapy is reocclusion. The fibrinolytic system works to remove fibrin deposits from the vascular wall, but in most occluded vessels, the vascular wall is impaired because of endothelial injury as well as plaque formation. After the removal of fibrin, such vascular impairment

${ }^{\square}$ Corresponding author: Janusz Szemraj, Department of Biochemistry Medical University of Łódź, 92-215 Łódź, Mazowiecka 6/8, Poland; tel.: (48) 42678 2465; e-mail: jszemraj@csk.am.lodz.pl

Abbrevations: BSA, bovine serum albumin; $\mathrm{C}_{50}$, concentration necessary for $50 \%$ clot lysis; HBS, Hepes-buffered saline; $\mathrm{hPlg}$, human plasminogen; K2 t-PA, kringle 2 domain of tissue type-plasminogen activator; RGD, Arg-Gly-Asp peptide; $\mathrm{SAK}$, staphylokinase; $\mathrm{T}_{50}$, time necessary for $50 \%$ clot lysis; $\mathrm{t}-\mathrm{PA}$, tissue type-plasminogen activator. 
results in recurrent activation of coagulation as well as platelets, and the damaged area becomes covered with platelet aggregates and a fibrin network. During thrombolysis a large amount of thrombin is released, which in turn activates the coagulation system, promotes platelet degranulation, and inhibits fibrinolysis. Thus, the benefit may be limited by incomplete reperfusion, and often by subsequent recanalization and reocclusion. To avoid the activation of thrombotic processes and early reocclusion, the thrombolytic agent is usually infused together with anthithrombotic and antiplatelet agents.

Staphylokinase (SAK), an extracellular profibrynolytic 136-amino-acid bacterial protein, is at least as potent as t-PA (tissue type-plasminogen activator) in the treatment of coronary artery recanalization (Armstrong et al., 2003; Moreadith \& Collen, 2003). The activation of plasminogen by SAK is highly fibrin-specific, and staphylokinase mutants could have an even better benefit/cost ratio than other thrombolytic agents. The exposure of positively charged $\mathrm{NH}_{2}$-terminal amino acids after hydrolysis by SAK is a major determinant of its plasminogenactivating potential. It enables the activation of plasminogen to plasmin on the thrombus surface without a systemic activation of the fibrinolytic system. As antibodies to SAK are expressed after administration, many SAK mutants has been examined to find molecules with lower antigenicity. Finally, PEG-SAK was tested for the treatment of acute myocardial infarction in a clinical trial (Moreadith \& Collen, 2003). Hence, there is an intense search for improving its clinically useful properties (Szarka et al., 1999; van Zyl et al., 2000; Icke et al., 2002; Lian et al., 2003; Wu et al., 2003).

In order to improve the thrombolytic potential of SAK as well as to introduce the antithrombotic and antiplatelet activities, the recombinant protein SAK-RGD-K2-Hir has been constructed (Szemraj et al., 2005). It has the fibrin-specific properties of plasminogen activation combined with antithrombin and antiplatelet activities and was previously shown to be a more potent and faster-acting thrombolytic agent compared with standard r-SAK in an in vitro study (Szemraj et al., 2005). To document the thrombolytic potential of SAK-RGD-K2-Hir we examined this protein in an electrically induced carotid artery thrombosis model and a stasis-induced venous model in rats (Szemraj et al., 2007). A weaker thrombolytic potency in the arterial thrombosis model was due to hirudin ( $r$-Hir) presence in molecule of SAKRGD-K2-Hir, since SAK-RGD-K2 was the most effective in maintaining of carotid potency and reduction of arterial thrombus mass. SAK-RGD-K2-Hir was significantly more effective in reduction of venous than arterial thrombus mass in our experimental conditions. A significant prolongation of bleeding time was observed in animals treated with proteins containing r-Hir (SAK-RGD-K2-Hir or SAK-K2-Hir). We have now constructed a new r-SAK variant with thrombolytic and antiplatelet properties and better antithrombin activity. SAK-RGD-K2-Hirul contains a fibrin-specific binding site of tissue type-plasminogen activator: the kringle 2 domain (K2), the ArgGly-Asp (RGD) peptide sequence for prevention of platelet aggregation, and an antithrombotic agent - hirulog (r-Hirul) fused to the C-terminal part of r-SAK.

The biological activity of the recombinant SAK-RGD-K2-Hirul protein was studied in vitro and compared with that of r-SAK and SAK-RGD-K2-Hir.

\section{MATERIALS AND METHODS}

Bacterial and yeast strains and plasmids. Escherichia coli strain BL21 (DE3) and Pichia pastoris GS 115 strain (Invitrogen, Groningen, Netherlands) were used as hosts for recombinant plasmids.

Recombinant plasmid PCR T7TOPO TA with either the gene for SAK, cDNA for K2-tPA or for hirudin were transformed into BL21 (DE3) competent cells. Single stranded templates of all constructs were prepared and confirmed by sequencing. Inserts from these plasmids were used for construction of recombinant plasmid pPIC 9K-SAK-RGD-K2-Hir and SAK-RGD-K2-Hirul in Multi Copy pPIC 9K yeast expression vector (Invitrogen, Groningen, Netherlands).

Reagents. All reagents used were of analytical grade. The restriction and modification enzymes, as well as Taq DNA polymerase came from Promega (Madison, WI, USA). Oligonucleotides, mutagenic oligonucleotides and synthetic DNA for hirulog were synthesized at IDT (Coralville, IA, USA). Human plasminogen (hPlg) and urokinase were prepared as described by Deutsch and Metz (1970) and Lijnen et al. (1986). CNBr-activated Sepharose 4B was purchased from Pharmacia Biotech (Uppsala, Sweden). Recombinant hirudin came from Rhein Biotech (Duesseldorf, Germany).

PCR amplification and cloning of the SAK gene. Oligonucleotides used for PCR amplification of SAK gene from Staphylococcus aureus were as follows: forward 5' ATGCTCAAAAGAAGTTTATTATTT $3^{\prime}$ and reverse 5' TTTCTTTTCTATAACAACCTTTGT 3'. The amplification was accomplished by initial denaturation at $94^{\circ} \mathrm{C}$ for $3 \mathrm{~min}$ and 27 cycles at $94^{\circ} \mathrm{C}$ for $30 \mathrm{~s}$, at $72^{\circ} \mathrm{C}$ for $30 \mathrm{~s}$, at $58^{\circ} \mathrm{C}$ for $30 \mathrm{~s}$ and a final extension at $72^{\circ} \mathrm{C}$ for $10 \mathrm{~min}$. The product of $491 \mathrm{bp}$ was cloned into PCR T7TOPO TA vector and then recloned into $P$. pastoris Multi Copy $\mathrm{PPIC} 9 \mathrm{~K}$ at the SnaBI-EcoRI site using a forward primer 5' GGTACGTAATGCTCAAAAGAAGTTTATTATTT 3' 
containing the SnaBI restriction site and reverse primer 5' GTGAATTCTTTCTTTTCTATAACAACCTTTGT 3' containing the EcoRI site. Introduction of mutations (amino acid substitutions K35A, E65Q, K74R, D82A, K130T and K135R) to the staphylokinase wild-type gene cloned in PCR T7TOPO TA vector was carried out using a QuickChange sitedirected mutagenesis kit (Stratagene, La Jolla, CA, USA) and mutant oligonucleotide primers according to Collen et al. (1997). Nicked DNA carrying the desired mutations was transformed into Epicurian XL-Blue supercompetent cells and then recloned to pPICK 9K vector.

RNA purification, synthesis of cDNA for K2 t-PA and PCR amplification. Total cellular RNA was extracted from human endothelial cells using Trizol reagent method, a single-step purification protocol (Chomczyński \& Sacchi, 1987). Polyadenylated RNA was isolated using a standard protocol on oligo dT-cellulose. Poly(A) RNA (50 ng) was then used for cDNA synthesis by SuperScript II RNase Transcriptase System (Invitrogen, Groningen, Netherlands), using 12-18 (dT) primers. cDNA was amplified with the forward 5' ATGAAGAGAGGGCTCTGCTGTGTG $3^{\prime}$ and reverse 5' GCTTGGCAAAGATGGCAGCCTGCC $3^{\prime}$ primers specific for t-PA cDNA. PCR conditions were initial denaturation $3 \mathrm{~min}$ at $94^{\circ} \mathrm{C}$ and 30 cycles of $30 \mathrm{~s}$ at $94^{\circ} \mathrm{C}$, $30 \mathrm{~s}$ at $72^{\circ} \mathrm{C}$ and $30 \mathrm{~s}$ at $57^{\circ} \mathrm{C}$. The reaction mix was diluted 10x and amplified again with the forward 5' AACAGTGACTGCTACTTTGGG 3' and reverse 5' GCGAAACTGAGGCTGGCTGTACTG 3' nested primers specific for $\mathrm{K} 2 \mathrm{t}-\mathrm{PA} \mathrm{cDNA}$ at the same PCR conditions. The $315 \mathrm{bp}$ (K2 t-PA) product was resolved through a $6 \%$ polyacrylamide gel and after purification on Wizard columns (Promega Corp.) cloned into PCR T7TOPO TA vector.

Cloning and sequencing of SAK-RGD-K2Hirul. Synthetic dsDNA encoding a 20-amino-acid linker peptide (ARASGRGDGGDSGRGDGGRA) containing two RGD sequences, and carrying EcoRI and AvrII sites at the ends was cloned into recombinant pPIC 9K yeast expression vector behind previously cloned staphylokinase gene and transformed into $P$. pastoris cells. The K2 t-PA cDNA previously cloned in PCR T7TOPO TA vector was then recloned into pPICK 9K yeast expression vector behind the SAK-RGD sequence in the AvrII-NotI site using the following oligonucleotides: forward $5^{\prime}$ GCCTAGGAACAGTGACTGCTACTTTG 3' containing the AvrII site and reverse $5^{\prime}$ TGCGGCCGCGCGAAACTGAGGCTGGCTGTACTG 3' containing the NotI site. The amplification was accomplished by initial denaturation at $94^{\circ} \mathrm{C}$ for $3 \mathrm{~min}$ and 27 cycles at $94^{\circ} \mathrm{C}$ for $30 \mathrm{~s}$, at $72^{\circ} \mathrm{C}$ for $30 \mathrm{~s}$, at $58^{\circ} \mathrm{C}$ for $30 \mathrm{~s}$ and a final extension at $72^{\circ} \mathrm{C}$ for $10 \mathrm{~min}$. A synthetic peptide linker was added according to Szarka et al. (1999); to evoke a fusion between two domains, r-SAK and K2. The 60 bp synthetic DNA for hirulog (F-P-R-P-G-G-G-GD-F-E-E-I-P-E-E-Y-L-Q) cloned in PCR T7TOPO TA vector was then recloned into recombinant pPIC9K yeast vector in the NotI site and introduced into $P$. pastoris cells. The DNA for hirulog was cloned behind SAK-RGD-K2 using the following primers: forward 5' CGCGGCCGCGGTGATTTCCCACGTCGGGA 3' and reverse 5' GGCGGCCGCTCATTGTAAATATTCTTCTGG 3', both containing the NotI site at the ends. DNA cloned for hirulog behind SAK-RGD-K2 generated a 5-amino-acid linker RGRGD separated both (containing additional RGD sequence). Single stranded templates of all constructs were prepared and confirmed by sequencing. Recombinant plasmid pPIC 9K-SAK-RGD-K2-Hirul was digested with SacI to linearize it. $P$. pastoris spheroplasts were obtained by Zymolyase digestion (Sigma Aldrich, MO, USA). $P$. pastoris spheroplasts were transformed using lithium chloride method $\left(10^{3}\right.$ transformants per $\mu \mathrm{g}$ DNA).

Expression and purification of SAK-RGDK2-Hirul. The SAK-RGD-K2-Hirul fusion protein was produced in $P$. pastoris cells. The pPIC9K yeast protein expression system directs recombinant proteins to the medium provides rapid and high-yield production of recombinant proteins in a eukaryotic organism. Post-translational modification of the expressed proteins critical for their biological activity, is carried out by the host cells. Optimal expression of SAK-RGD-K2-Hirul protein was obtain by growing transformed cells in MGY medium (1.34\% Yeast Nitrogen Base, $1 \%$ glycerol, $0.0004 \%$ biotin, $0.004 \%$ histidine) at $30^{\circ} \mathrm{C}$ for approx. $16-18 \mathrm{~h}\left(\mathrm{OD}_{600} 3-4\right)$. Supernatants were stored at $-80^{\circ} \mathrm{C}$. Recombinant protein was separated by affinity chromatography on immobilized human plasminogen coupled to CNBr-activated Sepharose 4B (Rodrigues et al., 1999). For SAK-RGD-K2-Hirul detection, rabbit polyclonal anti-staphylokinase antibodies were used. During construction of the SAK-RGD-K2-Hirul recombinant plasmid the following plasmids were also obtained: r-SAK, SAK-RGD-K2-Hir, SAK-K2-Hir. The same expression and purification procedures were applied to encoded recombinant proteins: r-SAK, SAK-K2Hir and SAK-RGD-K2-Hir, which were then used to check the biological activity in vitro of each part of the SAK-RGD-K2-Hirul protein. Protein was quantified by the BCA (Pierce) assay.

Disulfide bond reshuffling. The disulfide bond reshuffling of SAK-K2-Hir, SAK-RGD-K2-Hirul or SAK-RGD-K2-Hir was performed based on the method of Chang (1994), with modification. Recombinant protein samples were dialyzed and concentrated to a final concentration of $50-70 \mu \mathrm{M}$ in $0.1 \mathrm{M}$ $\mathrm{NaHCO}_{3}$ buffer ( $\mathrm{pH}$ 8.3) to minimize dimer formation. The reshuffling process proceeded at $4^{\circ} \mathrm{C}$ over- 
night in a microcentrifuge tube by adding cysteine (Cys) and cystine (Cys-Cys) to final concentrations of 4 and $2 \mathrm{mM}$, respectively. The efficiency of the reshuffling process was detected by non-reducing SDS/PAGE and Western blotting.

Binding of SAK-RGD-K2-Hirul and SAKRGD-K2-Hir to fibrin or plasmin assayed with BIAcore system. Interactions between fibrin or plasmin and the studied proteins: r-SAK, SAK-RGD-K2Hirul and SAK-RGD-K2-Hir were investigated in the BIAcore $\mathrm{X}$ system (BIAcore AB, Uppsala, Sweden) and the measurements were carried out on the surface of a CM5 biosensor. Both fibrinogen and plasminogen were immobilized at the sensor surface by an amine coupling procedure according to the standard method described by the producer. The instrument was set to maintain a temperature of $37^{\circ} \mathrm{C}$ at the sensor surface.

Fibrinogen, used for the immobilization at a concentration of $10 \mu \mathrm{g} / \mathrm{ml}$ in $10 \mathrm{mM}$ sodium acetate buffer, $\mathrm{pH}$ 5.0, was converted immediately to fibrin by enzymatic digestion with thrombin $(2 \mathrm{U} / \mathrm{ml}, 15$ $\mathrm{min}, 5 \mu \mathrm{l} / \mathrm{min}$ ). The digestion process was clearly observed as a time-dependent decrease in resonance response. The elution of the released fibrinopeptides continued until the baseline stabilized. The studied recombinant proteins were subsequently injected at a series of concentrations: $100,50,25$, and $12 \mu \mathrm{g} / \mathrm{ml}$ and contact with fibrin was permitted for $2 \mathrm{~min}$. During this period the complexes were formed and the appropriate resonance response was recorded. After that, the dissociation of the formed complexes was recorded and analyzed. The surface of the sensor chip was regenerated after each experiment by the injection of $10 \mu \mathrm{l}$ of $5 \mathrm{mM} \mathrm{HCl}$.

Plasminogen was also used for immobilization at a concentration of $10 \mu \mathrm{g} / \mathrm{ml}$ in $10 \mathrm{mM}$ sodium acetate buffer, $\mathrm{pH}$ 5.0. The immobilized hPlg was allowed to convert to plasmin under constant flow (5 $\mu \mathrm{l} / \mathrm{min})$ of HBS buffer $(0.01 \mathrm{M}$ Hepes, $0.13 \mathrm{M} \mathrm{NaCl}$, $\mathrm{pH}$ 7.4). This process was observed as a time-dependent decrease in the resonance response during several tens of minutes until the baseline stabilized. Then the studied proteins were applied onto the sensor at a concentration of $10 \mu \mathrm{g} / \mathrm{ml}$ and allowed to interact with plasmin for 4 min to permit the formation of complexes. Cessation of injection resulted in dissociation of the formed complexes. Both association and dissociation processes, observed as changes in the resonance response, were recorded and used for further calculations. The kinetic parameters $k_{\mathrm{a}}$ and $k_{\mathrm{d}}$ and kinetic constants $K_{\mathrm{A}}$ and $K_{\mathrm{D}}$ were then calculated using the BIAcore evaluation software. The molecular masses of the recombinant proteins were taken into consideration to compare binding of the recombinant constructs at equimolar concentrations.
Activation of human plasminogen by SAKRGD-K2-Hirul. The activity of r-SAK, SAK-RGDK2-Hirul and SAK-RGD-K2-Hir, revealed as conversion of $\mathrm{hPlg}$ to plasmin (hPlm), was measured using a coupled assay. A solution of $5 \times 10^{-9} \mathrm{M} \mathrm{hPlg}$ in 50 $\mathrm{mM}$ Hepes buffer, $\mathrm{pH} 7.4$, containing $0.01 \%$ Tween 80 , was supplemented with $5 \times 10^{-9} \mathrm{M}$ of recombinant proteins, and then the chromogenic substrate S2251 (Chromogenix, Uppsala, Sweden) was added to a final concentration of $0.9 \times 10^{-3} \mathrm{M}$. The release of $p$-nitroanilide was monitored continuously for $1 \mathrm{~h}$ at $37^{\circ} \mathrm{C}$ on a microplate reader (EL 340 BIO-TEK Instr.) at $405 \mathrm{~nm}$ according to Miele et al. (1999). The kinetics of plasminogen activation was determined as described by Vanwetswinkel et al. (2000) using various concentrations of $\mathrm{hPlg}\left(125 \times, 250 \times, 500 \times 10^{-9} \mathrm{M}\right)$. Generated plasmin was measured with $0.3 \mathrm{mM}$ S2403 substrate (Chromogenix) at different time intervals (0-10 $\mathrm{min})$.

Fibrinolytic, fibrinogenolytic and plasminogen activation properties of recombinant proteins. The fibrinolytic and fibrinogenolytic properties of r-SAK, SAK-RGD-K2-Hirul and SAK-RGD-K2-Hir were determined in human plasma using fibrin labeled with (iodine-125) ${ }^{125}$ I-fibrin clot according to Collen et al. (1996). After the addition of ${ }^{125} \mathrm{I}$-labeled human fibrinogen $(1 \mathrm{mg} / \mathrm{ml})$ to normal human pooled plasma, it was clotted with thrombin $(2 \mathrm{U}$ $\mathrm{NIH} / \mathrm{ml}$ ) and $35 \mathrm{mM} \mathrm{CaCl}$ according to Collen et al. (1996). The lysis of ${ }^{125} \mathrm{I}$-fibrin-labeled plasma clots by SAK-RGD-K2-Hir was monitored by measuring changes in clot turbidity at $25^{\circ} \mathrm{C}$. An equieffective concentration of SAK-RGD-K2-Hirul and SAK-RGDK2-Hir required to obtain a $50 \%$ clot lysis $\left(\mathrm{C}_{50}\right)$ within $2 \mathrm{~h}$ at $37^{\circ} \mathrm{C}$ was determined from plots of percent lysis versus the concentration of test compound required to obtain a $50 \%$ clot lysis.

Fibrin clot lysis analysis was performed in a microtiter plate at room temp. using a Titertek Twinreader (Flow Laboratories) to monitor the changes in turbidity at $405 \mathrm{~nm}$. Fibrin clots were obtained according to $\mathrm{Wu}$ et al. (2003). The wells were loaded with thrombin (1 NIH unit/ml), human fibrinogen $(1 \mathrm{mg} / \mathrm{ml})$ in HBST buffer $(20 \mathrm{mM}$ Hepes, $\mathrm{pH} 7.4$, $150 \mathrm{mM} \mathrm{NaCl}, 0.1 \%$ Tween 80 ) and $10 \mathrm{mM} \mathrm{CaCl}_{2}$ and the mixtures incubated for $3 \mathrm{~h}$ at room temp. The formed clots were washed with HBST buffer, and then layered with a solution containing $1.5 \times 10^{-6}$ $\mathrm{M}$ hPlg and r-SAK, SAK-RGD-K2-Hir, or SAKRGD-K2-Hirul at varying concentrations $(25 \times, 50 \times$, $100 \times 10^{-3} \mathrm{M}$ ). After $30 \mathrm{~min}$ incubation the clots were washed, layered with $1.5 \mu \mathrm{M} \mathrm{hPlg}$ in HBS buffer (20 $\mathrm{mM}$ Hepes, $\mathrm{pH} 7.4,150 \mathrm{mM} \mathrm{NaCl}$ ) and the clot lysis was monitored until completion.

Clot lysis activity of recombinant proteins in a circulating plasma system in vitro. Thrombolytic activity of r-SAK was compared with that obtained 
for SAK-RGD-K2-Hirul and SAK-RGD-K2-Hir in the circulating plasma system containing ${ }^{125} \mathrm{I}$-labeled thrombus, as described by Matsuo et al. (1990). ${ }^{125}$ Ilabeled fibrinogen $\left(2 \times 10^{5}\right.$ c.p.m. $)$ was used to obtain the radioactive plasma clot. The radioactive thrombus was then transferred to the circulating plasma system. Recombinant staphylokinase, SAK-RGDK2-Hir or SAK-RGD-K2-Hirul were injected to the system at a final concentration of 5, 1.25 or 0.625 $\mu \mathrm{g} / \mathrm{ml}$ and left at $37^{\circ} \mathrm{C}$ for $6 \mathrm{~h}$. Plasma samples were taken before the injection, and at $1 \mathrm{~h}$ intervals during the experimental time. The degree of clot lysis was estimated from the radioactivity released and the recordings were expressed as the percentage of the original clot radioactivity. The total radioactivity recovered from the remaining plasma clot and circulating plasma was expressed as the percentage of the radioactivity in the original clot.

Antithrombin activity of SAK-RGD-K2Hirul. The antithrombin activity of SAK-RGD-K2Hirul versus SAK-RGD-K2-Hir and r-Hir was determined by the degree of chromogenic substrate S-2238 cleavage inhibition (Chromogenix, Sweden) (the inhibition of the amidolytic activity of human thrombin by r-Hir). Then, $1.5 \times 10^{-4} \mathrm{M} \mathrm{r-Hir,} \mathrm{SAK-}$ RGD-K2-Hir or SAK-RGD-K2-Hirul was incubated with $2.1 \times 10^{-7} \mathrm{M}$ thrombin in $50 \mu \mathrm{l}$ Tris-buffered saline, containing $0.1 \% \mathrm{BSA}, \mathrm{pH} 7.4$, for $1 \mathrm{~h}$ at $37^{\circ} \mathrm{C}$. The thrombin activity was measured by the increase of absorbance at $405 \mathrm{~nm}$ in a microplate reader (EL 340 BIO-TEK Instr.) during its incubation with 300 $\mu \mathrm{M}$ substrate S-2238 for $10 \mathrm{~min}$ at $37^{\circ} \mathrm{C}$ (Riesbeck et al., 1998). The hirulog activity was also confirmed by the thrombin clot assay. Fifty microliters of thrombin $\left(2 \times 10^{-13} \mathrm{M}\right)$ was added to $50 \mu \mathrm{l}$ of $\mathrm{r}-\mathrm{Hir}, \mathrm{SAK}-\mathrm{RGD}-$ K2-Hir, or SAK-RGD-K2-Hirul $(0 \times, 0.15 \times, 0.3 \times, 0.6 \times$ and $1 \times 10^{-12} \mathrm{M}$ ) in an assay buffer containing $0.12 \mathrm{M}$ $\mathrm{NaCl}, 0.01 \mathrm{M}$ sodium phosphate, $0.01 \% \mathrm{NaN}_{3}, 0.1 \%$ BSA, pH 7.4. After 5 min of mixing at room temp., $100 \mu \mathrm{l}$ of human plasma diluted 1:10 was added and mixed for $20 \mathrm{~s}$. The turbidity of the clot was monitored in a microplate reader (EL 340 BIO-TEK Instr.) at $405 \mathrm{~nm}$ at $0,15,30$ and $60 \mathrm{~min}$.

Quantification of clot-bound thrombin. Crosslinked fibrin clots were prepared by adding human thrombin (Sigma) at final concentrations from 0.1 to $2 \mathrm{NIH}$ units/ml to $4 \mathrm{mg} / \mathrm{ml}$ human fibrinogen (Sigma) in Hepes-buffered saline (HBS, $0.02 \mathrm{M}$ Hepes, $0.13 \mathrm{M} \mathrm{NaCl}, \mathrm{pH} 7.4$ ) containing $20 \mathrm{mM} \mathrm{CaCl}$, at room temp. After mixing, $100 \mu \mathrm{l}$ of the polymerizing solution was transferred to a microtiter plate (Lian et al., 2003). The clots were formed at room temp. for $2 \mathrm{~h}$. Two sets of fibrin clots were formed. The first set of fibrin clots was washed with $100 \mu \mathrm{l}$ of HBS followed by careful removal of the washing buffer. This step was repeated five times until no thrombin activity in the wash buffer was detected. The second set of clots were unwashed and used as the control to determine the ratio of thrombin incorporated into the fibrin clot. One houndred microliters of $560 \mu \mathrm{M}$ thrombin-specific chromogenic substrate ( $N$-( $p$-tosyl)Gly-Pro-Arg- $p$-nitroanilide, Sigma) was then added to each well and the color development was monitored over a $10-\mathrm{min}$ period at $37^{\circ} \mathrm{C}$ in the kinetic mode at $405 \mathrm{~nm}$ using a plate reader (EL 340 BIOTEK Instr.). Thrombin activity was expressed as the initial rate of color development $(\mathrm{mA} / \mathrm{min})$.

Thrombin inhibition assays. These assays were performed under two conditions with hirudin and its derivatives (SAK-RGD-K2-Hir and SAKRGD-K2-Hirul) as inhibitors. The first series was performed with thrombin freely in solution, while the second series was determined with clot-bound thrombin. For the first variant, increasing amounts of hirudin or its derivatives (final concentrations from 0 to $30 \mathrm{nM}$ ) were incubated with thrombin (final concentration: $1 \mathrm{NIH}$ unit $/ \mathrm{ml}$ ) at room temp. in HBS containing $0.2 \mathrm{mg} / \mathrm{ml}$ BSA (Lian et al., 2003). The reaction was started by the addition of $50 \mu \mathrm{l}$ of $560 \mu \mathrm{M}$ thrombin-specific chromogenic substrate to the thrombin/hirudin mixture $(50 \mu \mathrm{l})$. Thrombin activity was determined as described above. $\mathrm{IC}_{50}$ values of hirudin and its derivatives were then determined. To monitor the inhibition of the clot-bound thrombin activity by hirudin and its derivatives, each washed fibrin clot was incubated with $100 \mu \mathrm{l}$ of either HBS or inhibitors (75 nM). After incubation at room temp. for $1 \mathrm{~h}$, liquid was carefully removed without disturbing the clot, and the clot was then washed with HBS to remove any unbound inhibitors. Finally, chromogenic substrate was added to each clot and the rate of color development (at 405 $\mathrm{nm}$ ) was measured. The activity of the non-inhibited clot-bound thrombin was plotted over the thrombin concentrations used to form the clot. The amount of clot-bound thrombin inhibited by the inhibitor was determined as the differences of thrombin activities between the clots treated with the inhibitor and the clots treated with HBS.

Inhibition of platelet aggregation by SAKRGD-K2-Hirul. Blood platelets were isolated using a modified washing procedure, a modified Mustard method (Mustard et al., 19770, with modifications according to Walkowiak et al., 1989). The platelet washing procedure was repeated twice the platelets were suspended $\left(4 \times 10^{8}\right.$ platelets $\left./ \mathrm{ml}\right)$ in Hepes/ Tyrode buffer $(136 \mathrm{mM} \mathrm{NaCl}, 5.5 \mathrm{mM}$ dextrose, $2 \mathrm{mM} \mathrm{MgCl}{ }_{2}, 0.47 \mathrm{mM} \mathrm{NaHCO}_{3}, 2.7 \mathrm{mM} \mathrm{KCl}$ and $10 \mathrm{mM}$ Hepes, $\mathrm{pH}$ 7.3). The platelets were counted by photometric method (Walkowiak et al., 2000). The isolated platelets were incubated for $20 \mathrm{~min}$ at room temp. with either SAK-RGD-K2-Hirul, SAKRGD-K2-Hir $\left(1.5 \times, 7.5 \times, 15 \times, 30 \times 10^{-6} \mathrm{M}\right)$ or reference compounds at equimolar concentrations: RGD 
(Sigma Bio Sciences) and SAK-K2-Hir prior to their stimulation with $1 \mu \mathrm{g} / \mathrm{ml}$ of collagen type I (CHONO-LOG, Havertown, PA, USA). The aggregation test was performed in a dual channel aggregometer (APACT Labor, Ahrensburg, Germany) at $37^{\circ} \mathrm{C}$ for 10 min under continuous stirring (1000 r.p.m.). The results were recorded with a dual channel plotter. Aggregation results were expressed as percent inhibition of platelet aggregation.

Statistics. Data presented in figures and tables are the means \pm S.D. of duplicate determinations from 3 to 4 independent experiments. One-way analysis of variance (ANOVA) was used where applicable, and the differences with $P$ values less than 0.05 were considered statistically significant. Nonparametric analysis of variance (Kruskal-Wallis test) and the all-pairwise comparisons Connover-Inman test were used as the inference tests.

\section{RESULTS}

\section{Expression and purification of SAK-RGD-K2-Hirul}

Chimeric proteins SAK-RGD-K2-Hir, r-SAK, SAK-K2-Hir and SAK-RGD-K2-Hirul were expressed in $P$. pastoris cells, purified from the medium and characterized by Western blotting using polyclonal anti-SAK antibodies (Figs. 1A and B). SAK-RGDK2-Hir and SAK-RGD-K2-Hirul were purified on immobilized human plasminogen coupled to CNBractivated Sepharose (Fig. 1A). SAK-RGD-K2-Hir and SAK-RGD-K2-Hirul were purified to homogeneity for the analysis of their specific biological activity and compared with r-SAK. Total protein concentration in the medium was $35 \mu \mathrm{g} / \mathrm{ml}$, of which secreted SAK-RGD-K2-Hirul was $8.21 \mu \mathrm{g} / \mathrm{ml}$ (approx. $25 \%$ of whole amount medium proteins).

\section{Reshuffling of disulfide bonds in SAK-RGD-K2- Hirul}

P. pastoris strains has been shown to produce biologically active secretory proteins with disulfide bonds. The K2-tPA protein has two pairs of disulfide bonds, but in the case of hirudin there are three pairs of disulfide bonds and the cysteine residues involved in their formation are not arranged in a sequential manner. When purified SAK-RGD-K2-Hir and SAK-RGD-K2-Hirul proteins were analyzed by Western blotting, additional faster bands were observed under non-reducing SDS/PAGE. In contrast, after reduction, all forms of recombinant proteins migrated as a single band with the apparent molecular mass of $40 \mathrm{kDa}$ for SAK-RGD-K2-Hirul and 42.5 for SAK-RGD-K2-Hir (not shown). These data

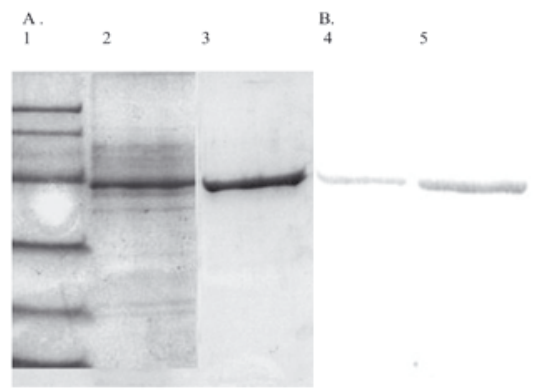

Figure 1. Purification of recombinant protein SAK-RGDK2-Hirul expressed in Pichia pastoris.

A. $10 \%$ SDS/PAGE of preparation of SAK-RGD-K2-Hirul. Lane 1, protein calibration mixture from Biorad (97400, $66200,45000,31000,21000,14400$, 6500); lane 2, recombinant protein SAK-RGD-K2-Hirul (approx. 41000) in growth medium; lane 3, purified preparation of the recombinant protein SAK-RGD-K2-Hirul. B. Western blot analysis with polyclonal anti-staphylokinase antibodies corresponding to gel in $\mathbf{A}$.

indicated that the recombinant proteins SAK-RGDK2-Hirul and SAK-RGD-K2-Hir had the correct pairing of cysteine residues.

\section{Kinetic assays on BIAcore}

The ability of the recombinant proteins to bind fibrin was assayed with fibrin clots immobilized on the biosensor was performed. We observed significant differences in the binding kinetics of these proteins, i.e., an approximately three-fold stronger fibrin binding by SAK-RGD-K2-Hirul and SAK-RGD-K2-Hir in comparison with r-SAK. The binding parameters calculated from the association and dissociation phases of the reaction curves are presented in Table 1. The lower $K_{\mathrm{D}}$ values for SAK-RGD-K2-Hirul and SAK-RGD-K2-Hir show a higher affinity and binding strength of these proteins to fibrin as compared with those of r-SAK. It means that the higher affinity and binding strength of these proteins to fibrin must be associated with the presence of the K2 domain of t-PA. We observed no differences between the parameters obtained for SAK-RGD-K2-Hirul and SAK-RGD-K2-Hir.

The calculated parameters of the binding and subsequent dissociation of SAK-RGD-K2-Hir, SAKRGD-K2-Hirul and SAK to human plasmin immobilized on the biosensor are shown in Table 2. The kinetic association rate constants $\left(k_{\mathrm{a}}\right)$, the apparent affinity equilibrium constants $\left(K_{\mathrm{A}}\right)$ and appropriate dissociation parameters for the binding of the derivatives of r-SAK to plasmin are similar to those of r-SAK alone, showing their comparable affinity to plasmin. The obtained results confirmed the biological activity of staphylokinase in the SAK-RGDK2-Hirul and SAK-RGD-K2-Hir hybrid proteins. The 
Table 1. Binding parameters of r-SAK, SAK-RGD-K2-Hir and SAK-RGD-K2-Hirul to fibrin

\begin{tabular}{lllll}
\hline & $k_{\mathrm{a}}\left(\mathrm{M}^{-1} \mathrm{~s}^{-1}\right)$ & $k_{\mathrm{d}}\left(\mathrm{s}^{-1}\right)$ & $K_{\mathrm{A}}\left(\mathrm{M}^{-1}\right)$ & $K_{\mathrm{D}}(\mathrm{M})$ \\
\hline r-SAK & $1.64 \pm 0.42 \times 10^{4}$ & $1.59 \pm 0.05 \times 10^{-2}$ & $1.07 \pm 0.29 \times 10^{6}$ & $9.53 \pm 2.34 \times 10^{-7}$ \\
SAK-RGD-K2-Hir & $4.72 \pm 1.31 \times 10^{4}$ & $1.28 \pm 0.08 \times 10^{-2}$ & $3.56 \pm 1.12 \times 10^{6}$ & $2.91 \pm 1.12 \times 10^{-7}$ \\
SAK-RGD-K2-Hirul & $4.96 \pm 0.10 \times 10^{4}$ & $1.02 \pm 0.01 \times 10^{-2}$ & $3.79 \pm 0.11 \times 10^{6}$ & $2.62 \pm 0.07 \times 10^{-7}$ \\
\hline
\end{tabular}

Kruskal-Wallis test and all-pairwise comparisons Connover-Inman test revealed significant differences between the parameters $K_{\mathrm{A}}$ and $K_{\mathrm{D}}$ obtained for r-SAK compared to recombinant proteins containing K2 domain ( $K_{\mathrm{A}}$ : r-SAK vs. SAK-RGD-K2-Hir $P=0.0018$, SAK-RGD-K2Hirul $P=0.0017$ and $K_{\mathrm{D}}$ : r-SAK vs. SAK-RGD-K2-Hir $P=0.0036$, SAK-RGD-K2-Hirul $P=0.0024$ ), whereas differences between parameters obtained for two chimeric variants were not significant.

Table 2. Binding parameters of r-SAK, SAK-RGD-K2-Hir and SAK-RGD-K2-Hirul to plasmin

\begin{tabular}{lllll}
\hline & $k_{\mathrm{a}}\left(\mathrm{M}^{-1} \mathrm{~s}^{-1}\right)$ & $k_{\mathrm{d}}\left(\mathrm{s}^{-1}\right)$ & $K_{\mathrm{A}}\left(\mathrm{M}^{-1}\right)$ & $K_{\mathrm{D}}(\mathrm{M})$ \\
\hline r-SAK & $8.58 \pm 0.27 \times 10^{4}$ & $7.93 \pm 0.08 \times 10^{-3}$ & $1.20 \pm 0.11 \times 10^{7}$ & $10.45 \pm 0.24 \times 10^{-8}$ \\
SAK-RGD-K2-Hir & $1.02 \pm 0.11 \times 10^{5}$ & $7.61 \pm 0.14 \times 10^{-3}$ & $1.37 \pm 0.13 \times 10^{7}$ & $7.42 \pm 0.09 \times 10^{-8}$ \\
SAK-RGD-K2-Hirul & $1.01 \pm 0.09 \times 10^{5}$ & $7.65 \pm 0.08 \times 10^{-3}$ & $1.34 \pm 0.23 \times 10^{7}$ & $7.43 \pm 0.05 \times 10^{-8}$ \\
\hline
\end{tabular}

Analysis of variance with ANOVA test revealed non-significant difference of parameters obtained for r-SAK when compared with other recombinant proteins. Differences between parameters obtained for two chimeric proteins are also not significant.

formation of complexes of SAK-RGD-K2-Hirul and SAK-RGD-K2-Hir with plasmin proceeds similarly to that of r-SAK-plasmin suggesting that addition of K2-tPA and hirulog did not change the staphylokinase activity.

Fibrinolytic, fibrinogenolytic and plasminogen activation properties of recombinant proteins

The concentration of r-SAK, SAK-RGD-K2Hirul and SAK-RGD-K2-Hir causing 50\% fibrinogen degradation after $2 \mathrm{~h}$ in normal human plasma in the absence of fibrin are shown in Table 3. The SAK-RGD-K2-Hir and SAK-RGD-K2-Hirul proteins exhibited a higher clot lysis activity as compared to r-SAK. We did not observe differences between the clot lysis activity of SAK-RGDK2-Hirul and SAK-RGD-K2-Hir. The presented values were determined from four independent experiments. Using fibrin clot lysis assay the introduction of the K2 domain to SAK-RGD-Hirul and SAK-RGD-K2-Hir changed the speed of fibrin degradation as compared to r-SAK. The analysis of $\mathrm{T}_{50}$ value (time required for $50 \%$ clot lysis) car- ried out at $50 \mathrm{mM}$ r-SAK, SAK-RGD-K2-Hirul and SAK-RGD-K2-Hir concentrations showed a significant difference (Fig. 2). The $\mathrm{T}_{50}$ values for r-SAK were $121 \pm 4.1 \mathrm{~min}$ (clot not washed, average from five experiments) and $182 \pm 3.1 \mathrm{~min}$ (clot washed), while the $\mathrm{T}_{50}$ values for SAK-RGD-K2-Hirul were $94.2 \pm 2.8 \mathrm{~min}$ (clot not washed) and $116 \pm 2.6 \mathrm{~min}$ (clot washed) and $104 \pm 4.1 \mathrm{~min}$ (clot not washed) and $118 \pm 3.1 \mathrm{~min}$ (clot washed) for SAK-RGD$\mathrm{K} 2$-Hir. The ratio of $\mathrm{T}_{50}$ for r-SAK:SAK-RGD-K2Hirul was 1.28 (clot not washed) and 1.56 (clot washed), r-SAK:SAK-RGD-K2-Hir 1.16 (clot not washed) and 1.54 (clot washed). We observed a significant increase of thrombus lysis rate by SAKRGD-K2-Hirul as compared with r-SAK (from $22.15 \%$ to over $36.3 \%$ ) and SAK-RGD-K2-Hir (from $14 \%$ to over $35.2 \%)$. The kinetic constans: catalytic rate constant $\left(k_{\text {cat }}\right)$ and Michaelis constant $\left(K_{\mathrm{m}}\right)$ for human plasminogen activation by the SAK-RGDK2-Hirul-plasmin and SAK-RGD-K2-Hir-plasmin complexes were calculated from Lineweaver-Burk plots (Table 3); they were similar for SAK-RGDK2-Hirul and SAK-RGD-K2-Hir and comparable to those of r-SAK.

Table 3. Fibrinolytic and amidolytic properties of r-SAK, SAK-RGD-K2-Hir and SAK-RGD-K2-Hirul in vitro

\begin{tabular}{|c|c|c|c|c|}
\hline & $\begin{array}{l}\text { Fibrinolytic } \\
\text { potency } \\
\mathrm{C}_{50}[\mu \mathrm{g} / \mathrm{ml}]\end{array}$ & $\begin{array}{l}\text { Fibrinogenolytic } \\
\text { potency } \\
\mathrm{C}_{50}[\mu \mathrm{g} / \mathrm{ml}]\end{array}$ & $\begin{array}{l}\text { Plasminogen } \\
\text { activation } \\
K_{\mathrm{M}}[\mu \mathrm{M}]\end{array}$ & $\begin{array}{l}\text { Plasminogen } \\
\text { activation } \\
k_{\text {cat }}\left[\mathrm{s}^{-1}\right]\end{array}$ \\
\hline r-SAK & $0.24 \pm 0.03$ & $33 \pm 3$ & $2.11 \pm 0.08$ & $1.85 \pm 0.09$ \\
\hline SAK-RGD-K2-Hir & $0.13 \pm 0.02$ & $38 \pm 2$ & $2.24 \pm 0.12$ & $1.89 \pm 0.12$ \\
\hline SAK-RGD-K2-Hirul & $0.12 \pm 0.01$ & $38 \pm 1$ & $2.12 \pm 0.12$ & $1.83 \pm 0.13$ \\
\hline
\end{tabular}

$\mathrm{C}_{50}$ indicates the concentration of variant SAK required for $50 \%$ clot lysis or 50\% fibrinogen breakdown in $2 \mathrm{~h}$. Analysis of variance of fibrinolytic potency with ANOVA test performed for r-SAK/SAK-RGD-K2-Hirul $(P<0.001)$ and r-SAK/SAK-RGD-K2-Hir $(P<0.001)$ showed significant difference between these groups, but differences between parameters obtained for two chimeric proteins are not significant $(P$ $=0.061)$. Fibrinogenolytic potency and kinetic constans $K_{\mathrm{m}}$ and $k_{\text {cat }}$ were not significantly different between compared proteins. 


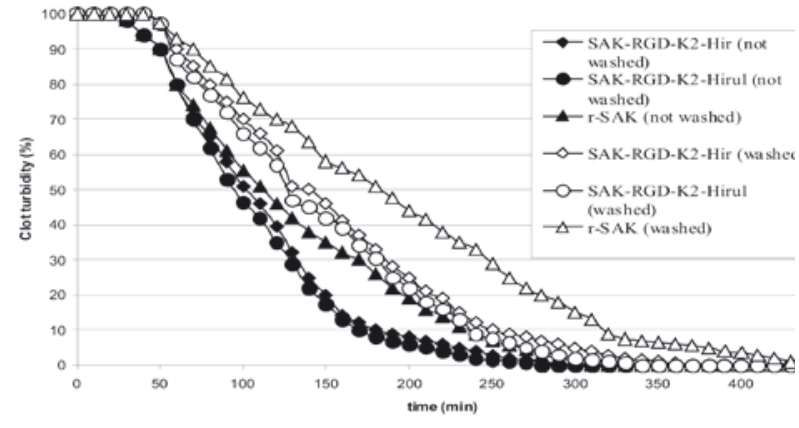

Figure 2. Turbidimetric fibrinolysis of recombinant proteins r-SAK, SAK-RGD-K2-Hir and SAK-RGD-K2-Hirul. Turbidity time course of fibrin clot lysis by r-SAK, SAKRGD-K2-Hir and SAK-RGD-K2-Hirul at $50 \mathrm{mM}$ in a solution containing $1.5 \mu \mathrm{M}$ human plasminogen. Clots were incubated with r-SAK, SAK-RGD-K2-HIR or SAK-RGDK2-Hirul for the entire period for $30 \mathrm{~min}$, then were washed with buffer.

\section{Clot-lysis activity of recombinant proteins}

To evaluate the thrombolytic potency of the recombinant proteins, the degree of thrombolysis induced by different amounts of recombinant staphylokinase, SAK-RGD-K2-Hirul or SAK-RGD-K2-Hir (5, 1.25 and $0.125 \mu \mathrm{g} / \mathrm{ml}$ ) was studied in circulating human plasma containing ${ }^{127}$ I-labeled plasma clot (Fig. 3 ). Dose-depenent lysis of ${ }^{127} \mathrm{I}$-labeled fibrin human clots submerged in human plasma was obtained for r-SAK, SAK-RGD-K2-Hirul and SAK-RGD-K2-Hir. The speed of thrombolysis of radioactive thrombus by SAK-RGD-K2-Hirul or SAK-RGD-K2-Hir was double that of r-SAK. Fifty percent thrombolysis of

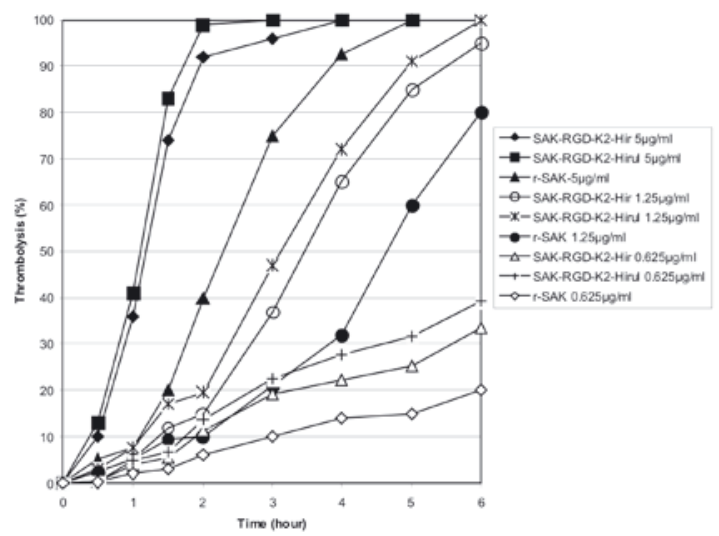

Figure 3. Clot lysis activity of recombinant proteins: SAK-RGD-K2-Hirul, SAK-RGD-K2-Hir and r-SAK.

The extent of thrombolysis of radioactive thrombus was expressed as percentage of original clot radioactivity released upon incubation with varying concentrations of recombinant staphylokinase, SAK-RGD-K2-Hirul or SAKRGD-K2-Hir. Data represent means \pm S.D. for triplicate experiments. There are statisticaly significant differences in thrombolytic activity between SAK-RGD-K2-Hirul, SAKRGD-K2-Hir and r-SAK obtained for each tested concentration of recombinant proteins $(P<0.001)$. the orginal clot was obtained in $1.06 \pm 0.07 \mathrm{~h}$ for 5 $\mu \mathrm{g} / \mathrm{ml}$ SAK-RGD-K2-Hirul and $1.17 \pm 0.05 \mathrm{~h}$ for SAKRGD-K2-Hir, while the same thrombolytic effect for $5 \mu \mathrm{g} / \mathrm{ml}$ by $\mathrm{r}-\mathrm{SAK}$ was observed in $2.18 \pm 0.11 \mathrm{~h}$ which shows their higher thrombolytic potency. Thrombolysis was slightly faster for SAK-RGD-K2Hirul than for SAK-RGD-K2-Hir with varying concentration of recombinant proteins $(5 \mu \mathrm{g} / \mathrm{ml}$ by $12 \%$, $1.25 \mu \mathrm{g} / \mathrm{ml}-14 \%$, and $0.125 \mu \mathrm{g} / \mathrm{ml}-15 \%$.)

\section{Antithrombotic activity of SAK-RGD-K2-Hirul}

To provide evidence that the recombinant SAKRGD-K2-Hirul protein binds to thrombin, its ability to inhibit the activity of thrombin using amidolytic assay was investigated (Fig. 4). Our results show that inhibition of the thrombin catalytic activity by SAK-RGDK2-Hirul was almost identical to that by recombinant hirudin and slightly higher (several percent) than that by SAK-RGD-K2-Hir. In the chromogenic assay 150 $\mu \mathrm{M}$ SAK-RGD-K2-Hirul, similarly to r-Hir, was sufficient to inhibit the action of thrombin significantly, while r-SAK alone was unable to inhibit the amidolytic activity of thrombin. It could suggest that the recombinant fusion protein contains an active binding site of hirudin, thus inhibiting thrombin catalytic activity.

These results were confirmed by the fibrin clot assay, when human plasma was used as a source of fibrinogen. SAK-RGD-K2-Hirul protein at different concentrations $(0.15,0.3,0.6$ and $1 \mathrm{pM})$ similarly to r-hirudin, inhibited completely the clotting activity of thrombin. As shown in Fig. 5 the addition of thrombin increased the turbidity due to the fibrin clot formation.

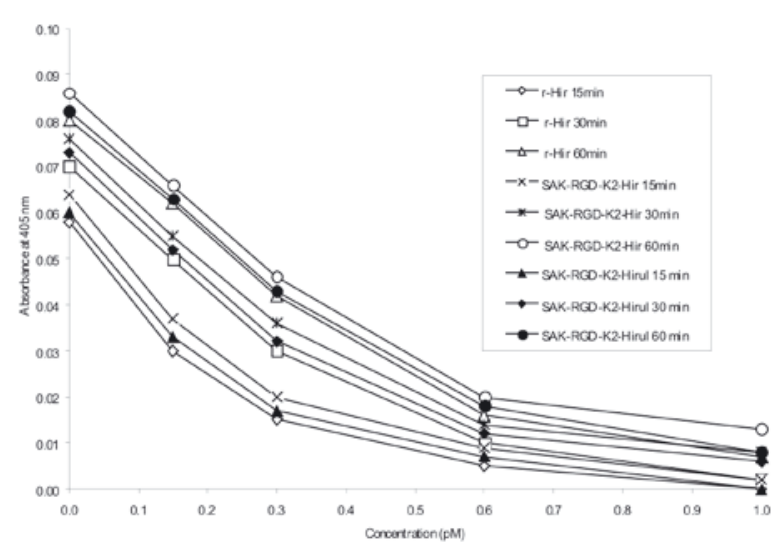

Figure 4. Inhibition of antithrombotic activity by recombinant recombitant proteins SAK-RGD-K2-Hirul, SAKRGD-K2-Hir or r-hirudin.

Thrombin (0.2 pM) was incubated with r-Hir, SAK-RGDK2-Hirul or SAK-RGD-K2-Hir (at 0, 0.15, 0.3, 0.6, 1 pM). Turbidity of clot was monitored by microplate reader at $0,15,30,60 \mathrm{~min}$. Data represent means \pm S.D. for triplicate experiments. No differences in antithrombotic activities between proteins analyzed at a given conecentration $(P=0.065)$. 


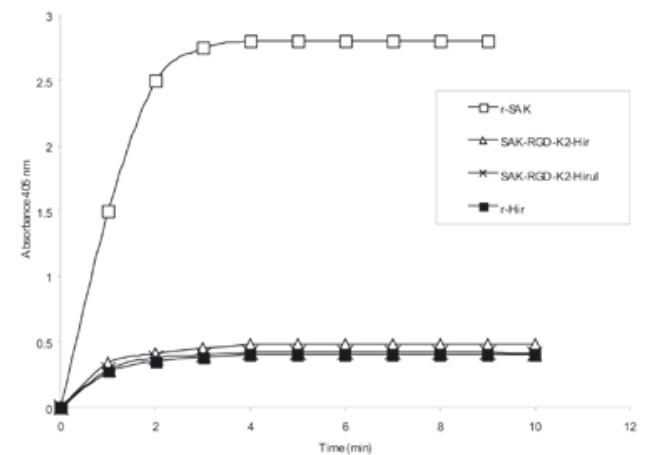

Figure 5. Antithrombotic activity of the recombinant proteins r-hirudin, r-SAK, SAK-RGD-K2-Hir and SAKRGD-K2-Hirul expressed as inhibition of thrombin amidolytic activity.

Thrombin $(210 \mathrm{nM})$ activity was determined with substrate S-2238 $(300 \mu \mathrm{M})$ for $10 \mathrm{~min}$ at $37^{\circ} \mathrm{C}$ in a microplate reader (EL340BIOTEK Intr.). Recombinant proteins were at $150 \mu \mathrm{M}$. Data represent means \pm S.D. for triplicate experiments. There are no significant statistic differences in antithrombotic activity between SAK-RGD-K2-Hir, SAKRGD-K2-Hirul and r-Hir obtained for each concentration of recombinant proteins $(P=0.062)$.

\section{Quantification of clot-bound thrombin and thrombin inhibition assays}

Thrombin binds to fibrin directly through an interaction at its anion-binding exosite. Washed fibrin clots formed in the presence of different amounts of thrombin were used in this study. The concentration of hirudin, SAK-RGD-K2-Hir or SAK-RGD-K2-Hirul of $75 \mathrm{nM}$ was selected because the clinical doses of SAK used in thrombolysis are usually in the range of 64-192 nM in circulation (Collen \& van de Vert, 1993). After several washes to remove any unbound hirudin, SAK-RGD-K2-Hir or SAK-RGD-K2-Hirul, thrombin activity within these fibrin clots was determined (Fig. 6A). When the clots were formed with low doses of thrombin (up to $1.5 \mathrm{NIH}$ units/ml), SAK-RGD-K2Hirul and SAK-RGD-K2-Hir were equally effective. For fibrin clots formed in the presence of higher levels of thrombin (1.5-3 NIH units/ ml) SAK-RGD-K2-Hirul was by around $5 \%$ more effective than SAK-RGD-K2Hir in inhibition of clot-bound thrombin. This is so probably because of the smaller size of hirulog versus hirudin so that it can diffuse more easily into the interior of the clot. The differences of thrombin activities between the clots treated with hirudin, SAK-RGD-K2Hirul, SAK-RGD-K2-Hir and HBS (control) showed a thrombin dose-dependent inhibition mediated slightly better $(5 \%)$ by SAK-RGD-K2-Hirul compared with SAK-RGD-K2-Hir (Fig. 6B).

\section{Antiplatelet activity of SAK-RGD-K2-Hirul}

In the next set of experiments we investigated the interaction of recombinant staphyloki-
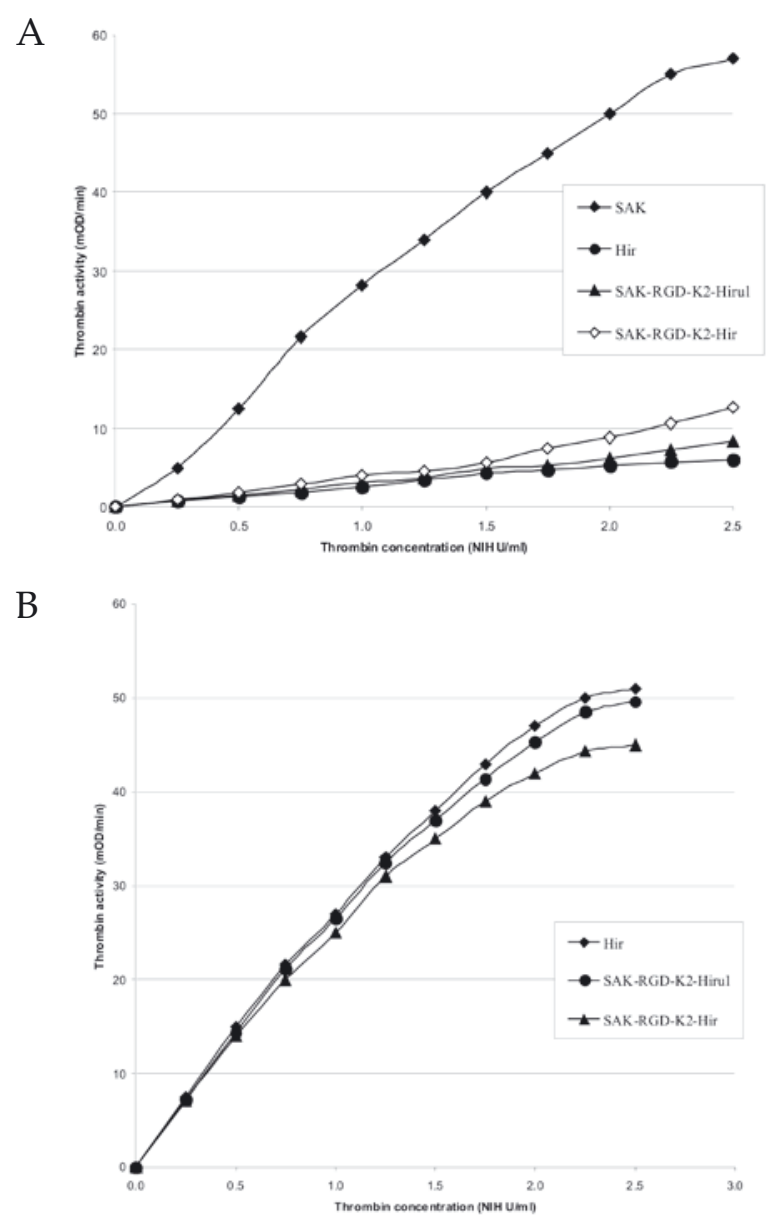

Figure 6. Inhibition of clot-bound thrombin activity by rSAK, Hir, SAK-RGD-K2-Hir and SAK-RGD-K2-Hirul.

A. Clot-bound thrombin activity from washed clots was determined in the presence of hirudin, r-staphylokinase, SAK-RGD-K2-Hir and SAK-RGD-K2-Hirul. B. The amount of clot-bound thrombin activity inhibited was determined as the differences of thrombin activities between the clots treated with the hirudin, SAK-RGD-K2-Hir or SAK-RGDK2-Hirul and the clots treated with HBS.

nase, SAK-RGD-K2-Hirul, SAK-RGD-K2-Hir, SAKK2-Hir and RGD-peptide with human platelets in vitro. A low inhibitory effect of r-SAK-K2-Hir on the aggregation of washed platelets was obtained as compared with that of SAK-RGD-K2-Hirul and SAK-RGD-K2-Hir (Fig. 7). A significant inhibition of platelet aggregation was obtained at $1.5-30 \mathrm{nM}$ of SAK-RGD-K2-Hirul. The platelet disaggregation was comparable with RGD-peptide alone (Fig. 7). A similar inhibitory effect on platelet aggregation was detected at 1.5-7.5 nM of SAK-RGD-K2-Hirul, SAK-RGD-K2-Hir and RGD sequence, whereas at concentrations of $15-30 \mathrm{nM}$ a diminished inhibitory effect was observed by, respectively 19\%, 38.3\% for SAK-RGD-K2-Hir, $26 \%$ ，44.4\% for SAK-RGD-K2Hirul and $32 \%, 51 \%$ for RGD. Recombinant SAKK2-Hir, SAK-RGD-K2-Hirul and SAK-RGD-K2-Hir did not affect the ADP and collagen-induced aggregation (not shown). 


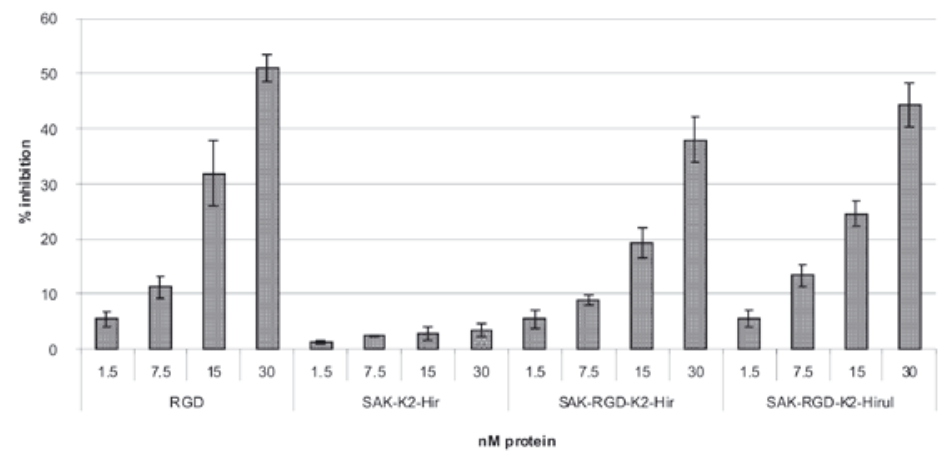

Figure 7. Comparison of percentage inhibition of platelet aggregability assessed in the aggregation test.

Aggregation of washed human platelets was induced by thrombin $(0.1 \mathrm{U} / \mathrm{ml})$. The means \pm S.E.M. came from the three separate experiments.

\section{DISCUSSION}

A frequent problem in thrombolytic therapy is reocclusion. The fibrinolytic system works to remove fibrin deposits from the vascular wall, but in most occluded vessels, the vascular wall is impaired because of endothelial injury as well as plaque formation. After the removal of fibrin, such vascular impairment again results in activation of coagulation as well as platelets, and the damaged area becomes covered with platelet aggregates and a fibrin network. As we have no agent that can promote regeneration of the damaged vascular wall, reocclusion is a serious problem in thrombolytic therapy. To avoid reocclusion, an anticoagulant, such as heparin or low-molecular-weight heparin has been used as adjunctive therapy (Arjomand et al., 2004) in some clinical trials. In other cases, an antiplatelet, such as aspirin, or a GPIIb/IIIa blocker, are used.

The ideal thrombolytic agent should, therefore, possess high affinity for fibrin and express high plasminogen activator activity on the fibrin (thrombus) surface, as well as antiplatelet and anticoagulant activity at the damaged vascular surface. After administration into the circulation, it should be delivered specifically to the thrombus (via its high affinity for fibrin) and generate plasmin on the thrombus. The plasmin digests fibrin and restores blood flow. This ideal thrombolytic agent then acts to block platelet activation and coagulation at the newly exposed vascular surface, thereby preventing reocclusion. In our previous in vitro study (Szemraj et al., 2005) we described the biological activity of a new compound with four domains: (i) a plasminogen activator domain derived from SAK, (ii) a fibrin affinity domain containing a K2 motif derived from t-PA, (iii) an antiplatelet domain with Arg-Gly-Asp (RGD) sequences, (iv) an anticoagulant domain derived from hirudin. That newly developed compound apparently possessed all the required features of an ideal thrombolytic agent, and indeed exhibited rapid and potent clot lysis as well as antiplatelet and anticoagulant activities. Interestingly, the anti- platelet activity of the compound was comparable to that of the RGD sequences alone, which may indicate that the RGD sequences contained between the SAK and K2 moieties in the new agent lie on the surface of the molecule.

In our in vivo study (Szemraj et al., 2007) we tried to document the thrombolytic activity of SAKRGD-K2-Hir after bolus administration in arterial and venous thrombosis models in rats. In order to see how the thrombolytic effects of SAK-RGD-K2Hir depend on its molecule structure, the recombinant proteins SAK-K2-Hir and SAK-RGD-K2 were studied. Although SAK-RGD-K2-Hir caused arterial thrombus lysis, there was no significant reduction of thrombus mass in comparison with r-SAK-treated group. The main end points of arterial thrombolysis consisted of the frequency and rate of arterial recanalization and the persistence of patency. We observed that arterial patency after SAK-RGD-K2-Hir was not significantly greater in comparison to that after r-SAK or t-PA. The time to reperfusion after SAK-RGD-K2-Hir injection was also very similar in comparison to r-SAK-treated group. In the venous thrombosis model, however, SAK-RGD-K2-Hir was significantly more effective in lysis of thrombus than r-SAK.

The differences in the thrombolytic potency of SAK-RGD-K2-Hir in the two models may be related to the different composition of arterial and venous clot. Whereas the venous thrombus is mainly composed of a fibrin mesh enriched in red blood cells, in the arterial thrombus a high amount of structural blood elements dominates over the rather small amount of fibrin, which is the main target of the investigated recombinant proteins. The presence of dominating morphotic blood elements participating in arterial thrombus may constitute a peculiar spheric barrier for thrombolytic enzymes and underlie the limited accessibility of the protein to fibrin.

Our in vitro studies showed that the potency of thrombin inhibition by the hirudin part of the recombinant SAK-RGD-K2-Hir protein was the same as that of r-Hir alone (Szemraj et al., 2005). In this in vivo study we demonstrate that 
SAK-RGD-K2-Hir is more effective in the venoustype thrombolysis model. Other researchers also suggested that the antithrombotic effect of direct thrombin inhibitors is more pronounced in the venous study (Bakker et al., 1993). The thrombin inhibitory potential of the recombinant protein was revealed by findings of a dose-dependent prolongation of APTT and TT. This strongly suggested that the antithrombin activity depends on the r-Hir part of the SAK-RGD-K2-Hir molecule in our in vivo conditions. It was also shown that anticoagulants markedly inhibit platelet deposition in the venous-type thrombolysis model but they have little effect on platelet deposition onto collagen surface (Bakker et al., 1993).

In the present study, we report the construction of a new recombinant protein SAK-RGD-K2Hirul, a more potent antithrombin agent consisting of four functional modules: SAK, RGD, K2-tPA and Hirulog. Staphylokinase mutant (K35A, E65Q, K74R, D82A, K130T, K135R) (Collen et al., 1997; Szemraj et al., 2005), the first element of the chimera reveals properties similar to staphylokinase alone. The results obtained from three independent analyses of the interaction of staphylokinase and staphylokinase as a part of hybrid proteins with plasmin are similar to the results obtained by Okada et al. (2000). Those results demonstrated that the addition of RGD-K2-Hirul and RGD-K2-Hir to staphylokinase did not lead to an increase in $K_{\mathrm{m}}$ for the substrate plasminogen and that the SAK-plasmin enzyme complexes display an amidolytic activity comparable to that of the SAK-plasmin complex. The K2 domain of t-PA is involved in fibrin-dependent plasminogen activation, lysine binding and fibrin binding (Bakker et al., 1993; Horrevoets et al., 1994). The addition of the K2 domain resulted in a significant change of the biological properties of the protein. Our results indicate a higher binding affinity of SAK-RGD-K2-Hirul and SAK-RGD-K2Hir for intact fibrin. We observed an approximately three times stronger fibrin binding to SAK-RGD-K2Hirul and SAK-RGD-K2-Hir in comparison with $\mathrm{r}$ SAK. A decreased $K_{D}$ value for SAK-RGD-K2-Hirul and SAK-RGD-K2-Hir shows a higher affinity and binding strength of these proteins to fibrin as compared with r-SAK. Introduction of K2-tPA to r-SAK increased the thrombolytic and fibrinolytic efficiency of staphylokinase. Thrombolysis of radioactive thrombus by the recombinant proteins SAK-RGDK2-Hirul and SAK-RGD-K2-Hir was by 51\% (SAKRGD-K2-Hirul) or $46.3 \%$ (SAK-RGD-K2-Hir) faster compared to that by r-SAK. Lower concentrations of SAK-RGD-K2-Hirul and SAK-RGD-K2-Hir were required to obtain a $50 \%$ clot lysis in $2 \mathrm{~h}$ versus $\mathrm{r}$ SAK, which documents their higher potential in in vitro clot lysis. Analysis of the $\mathrm{T}_{50}$ value (time nec- essary for $50 \%$ clot lysis) carried out at $50 \mathrm{mM}$ of r-SAK and SAK-RGD-K2-Hirul revealed a significantly higher clot lysis rate for SAK-RGD-K2-Hirul protein as compared to that for r-SAK (by $22.15 \%$ to $36.5 \%$ for SAK-RGD-K2-Hirul, $14 \%$ to $35.2 \%$ for SAK-RGD-K2-Hir). The effect of contraction on clot lysis time by SAK-RGD-K2-Hirul was similar to that obtained by Wu et al. (2003) for a chimera containing the $\mathrm{K} 1$ domain of plasminogen. The addition of the K2-tPA domain significantly decreased the concentration of SAK-RGD-K2-Hirul and SAK-RGDK2-Hir necessary to reach the $C_{50}$ value compared with r-SAK. These results showed that recombinant proteins SAK-RGD-K2-Hirul and SAK-RGD-K2-Hir had similar biological activities as r-SAK, but their fibrin specificity was significantly increased.

The addition of the RGD sequence to recombinant staphylokinase resulted in the protein acquiring the ability to prevent platelet aggregation, the main component of the forming clot. We observed an effective block of platelet-platelet interaction comparable with that of the RGD sequence alone, while staphylokinase alone failed to inhibit platelet aggregation. It may result from chance plasmin formation (lack of $\alpha_{2}$-antiplasmin) causing degradation of fibrinogen and other proteins involved in the aggregation process. This phenomenon was not observed in platelet-rich plasma, confirming the results presented by others (Horrevoets et al., 1994). We introduced three RGD sequences (two in the 20-amino-acid linker peptide and another in the five amino-acids linker RGRGD separating SAK-RGD-K2 and hirulog) in the recombinant SAK-RGD-K2-Hirul protein. The efficiency of blocking the platelet-platelet interaction by SAK-RGD-K2-Hirul was around 7\% better than that of SAK-RGD-K2-Hir and comparable to that of the RGD sequence alone. These results showed that the recombinant protein SAK-RGDK2-Hirul containing the RGD sequences possesses the ability to block platelet aggregation and hence should be more effective in clot lysis than SAKK2-Hir.

Hirudin, which is the most potent and specific thrombin inhibitor, blocks the thrombin-dependent platelet activation without influencing the aggregation effect brought about by various factors. The weaker thrombolytic potency in the arterial thrombosis model was the result of hirudin ( $\mathrm{r}-$ Hir) presence in the molecule of SAK-RGD-K2-Hir (Szemraj et al., 2007). We have constructed a new SAK variant - SAK-RGD-K2-Hirul with hirulog instead hirudin. The addition of the smaller-size hirulog instead of hirudin as a part of the recombinant protein resulted in a strong interaction with thrombin. We obtained similar $K_{\mathrm{D}}$ values of the order of picomoles, similarly as for hirudin alone 
(not shown). Our results show that inhibition of the thrombin catalytic activity by SAK-RGD-K2Hirul was almost identical to that by recombinant hirudin and by several percent higher than by SAK-RGD-K2-Hir. Also for fibrin clots formed in the presence of higher levels of thrombin SAKRGD-K2-Hirul was by approx. $5 \%$ more effective than SAK-RGD-K2-Hir in inhibition of clot-bound thrombin.

In conclusion, our data indicate that recombinant protein SAK-RGD-K2-Hirul is a more potent and faster-acting clot-dissolving agent with better antithrombin and antiplatelet properties compared to r-SAK and SAK-RGD-K2-Hir. The animal model of venous and arterial thrombosis was used to verify the biological activity of recombinant protein SAK-RGD-K2-Hiul in vivo and has demonstrated the efficacy of RGD-SAK in the lysis of platelet-rich coronary blood clots and in prevention of reocclusion after thrombolysis. The ongoing studies on SAKRGD-K2-Hirul fusion protein will provide futher details about their therapeutic potential from animal models of thrombosis in vivo.

\section{Acknowledgements}

This work was supported by a research project of the Foundation for the Development of Polish Pharmacy and Medicine - Polpharma.

\section{REFERENCES}

Arjomand H, Cohen M, Ezekowitz MD (2004) Combination antithrombotic therapy with antiplatelet agents and anticoagulants for patients with atherosclerotic heart disease. J Invasive Cardiol 16: 271-278.

Armstrong PW, Burton J, Pakola S, Molhock PG, Betriu A, Tendera M, Bode C, Adgey A, Bar F, Vahanian A, Van der Werf F (2003) Collaborative angiographic patency trial of recombinant staphylokinase (Captors II). Am Heart J 146: 484-488.

Bakker A, van der Greef W, Rehberg E, Marotti K, Verheijen J (1993) Introduction of lysine and clot binding properties in the kringle one domain of tissue-type plasminogen activator. J Biol Chem 268: 18496-18501.

Chang JY (1994) Controlling the speed of hirudin folding. Biochem J 15: 643-650.

Chomczynski P, Sacchi N (1987) Single-step method of RNA isolation by acid qanidinium thiocyanate-phenolchloroform extraction. Anal Biochem 196: 156-159.

Collen D, Van de Werf F (1993) Coronary thrombolysis with recombinant staphylokinase in patients with evolving myocardial infarction. Circulation 87: 18501853.

Collen D, Lijnen HR (2000) Molecular basis of thrombolytic therapy. J Nucl Cardiol 7: 373-381.

Collen D, Bernaerts R, Declerck P (1996a) Recombinant staphylokinase variants with altered immunoreactivity. I. Construction and characterization. Circulation 94: 197-206.
Collen D, Moreau H, Stockx L, Vanderschueren S (1996b) Recombinant staphylokinase variants with altered immunoreactivity. II. Trombolytic properties and antibody induction. Circulation 94: 207-216.

Collen D, De Cock F, Demarsin E, Jenne S (1997) Recombinat staphylokinase variants with altered immunoreactivity III: species variability of antibody binding patterns. Circulation 95: 455-462.

Deutsch DG, Metz ET (1970) Plasminogen purification from human plasma by affinity chromatography. Science 170: 1095-1096.

Guarini S (1996) A highly reproducible model of arterial thrombosis in rats. J Pharmacol Toxicol Methods 35: 101105.

Horrevoets A, Smilde A, de Vries C, Pannekoek H (1994) The specific roles of finger and kringle 2 domains of tissue-type plasminogen activator during in vitro fibrinolysis. J Biol Chem 269: 12639-12644.

Icke Ch, Schlott B, Ohlenschlager OM, Guhrs K, Glusa E (2002) Fusion proteins with anticoagulant and fibrinolytic properties: funcional studies and structural considerations. Mol Pharmacol 62: 203-209.

Lian Q, Szarka SJ, Ng KS, Wond S-L (2003) Engineering of staphylokinase-based fibrinolytic agent with anthithrombotic activity and targeting capability towards thrombin-rich fibrin and plasma clots. J Biol Chem 278: 26677-26686.

Lijnen HR, Van Hoef B, Collen D (1986) Comparative kinetic analysis of the activation of human plasminogen natural and recombinant single-chain urokinase-type activator. Biochem Biophys Acta 884: 402-408.

Matsuo O, Okada K, Fukao H, Tomioka Y, Ueshima S, Watanuki M, Sakai M (1990) Thrombolytic properties of staphylokinase. Blood 76: 925-929.

Miele R, Prorok M, Costa A, Castellino FJ (1999) Glycosylation of asparagine-28 of recombinant staphylokinase with high-mannose-type oligosaccharides results in a protein with highly attenuated plasminogen activator activity. J Biol Chem 274: 7769-7776.

Moreadith RW, Collen D (2003) Clinical development of PEGylated recombinant staphylokinase (PEG-SAK) for bolus thrombolytic treatment of patients with acute myocardial infraction. Adv Drug Deliv Rev 55: 13351345.

Mustard JF, Perry DW, Ardlie NC, Pachman MA (1977) Preparation of suspensions of washed platelets from humans. Brit J Hamatol 22: 193-204.

Riesbeck K, Chen D, Kemball-Cook G, Mc Vey JH, George AJT, Tuddenham E, Dorling A, Lechler R (1998) Expression of hirudin fusion proteins in mammalian cells: a strategy for prevention of intravascular thrombosis. Circulation 98: 2744-2752.

Rodriques P, Hernandez L, Munoz E, Castro A, De la Fuente J, Herrera L (1999) Purification of streptokinase by affinity chromatography on immobilized acylated human plasminogen. Biotechnics 12: 424-429.

Szarka SJ, Sihota EG, Habibi HR, Wong SL (1999) Staphylokinase as a plasminogen activator component in recombinant fusion proteins. Appl Envir Microbiol 65: $506-513$

Szemraj J, Walkowiak B, Kawecka I, Janiszewska G, Buczko W, Bartkowiak J, Chabielska E (2005) A new recombinant thrombolytic and antithrombotic agent with higher fibrin affinity - a staphylokinase variant. I. In vitro study. J Tromb Haemost 3: 2156-2165.

Szemraj J, Stankiewicz A, Rozmysłowicz W, Mogielnicki A, Buczko W, Oszajca K, Bartkowiak J, Chabielska E (2007) A new recombinant thrombolytic and anti- 
thrombotic agent with higher fibrin affinity - a staphylokinase variant. In vivo study. Thromb Haemost 97: 1037-1045.

Ueshima S, Matsuo O (2006) Development of new fibrinolytic agents. Curr Pharm Des 12: 849-845.

van Zyl WB, Pretorius GH, Lamprecht S, Roodt JP, Kotzé HF (2000) PLAT SAK, a potent antithrombotic and fibrinolytic protein, inhibits arterial and venous thrombosis in baboon model. Thromb Res 98: 435-443.

Vanwetswinkel S, Plaisance S, Zhi-Young Z, Vanlinthout I, Brepoels K, Lasters I, Collen D, Jespers L (2000) Pharmacokinetic and thrombolytic properties of cysteinelinked polyethylene glycol derivatives of staphylokinase. Blood 95: 936-942.
Walkowiak B, Michalak E, Koziolkiewicz W, Cierniewski C (1989) Rapid photometric metod for estimation of platelet count in blood plasma or platelet suspension. Throm Res 56: 763-766.

Walkowiak B, Kralisz U, Michalec L, Majewska E, Koziołkiewicz W, Ligocka A, Cierniewski C (2000) Comparison of platelet aggregability and P-selectin surface expression on platelets isolated by different methods. Thromb Res 99: 495-502.

Wu S-C, Castellino FJ, Wong S-L (2003) A fast-acting, modular structured staphylokinase fusion with kringle 1 from human plasminogen as the fibrin targeting domain offers improved clot-lysis efficacy. J Biol Chem 278: 18199-18206. 